\title{
Myocardial Infarction and Subsequent Pregnancy
}

\author{
Citânia Lúcia Tedoldi, Waldomiro Carlos Manfroi
}

Porto Alegre, RS - Brazil

We report the case of a 40-year-old woman with 2 previous myocardial infarctions, revascularization surgery, and an ongoing pregnancy complicated with preeclampsia and fetal hypoxia. Her follow-up performed by a multidisciplinary team made possible the birth through cesarean section of a premature infant of the female sex with a very low birth weight, but without severe respiratory distress of the hyaline membrane disease type. Three months after the delivery, mother and daughter were healthy.

The prevalence of coronary heart disease in women of childbearing age is low when compared with that in men of the same age group. This difference, however, decreases as age increases. Coronary heart disease accounts for $5 \%$ of the deaths in women from 35 to 44 years of age in developed countries, such as the United States of America and the United Kingdom ${ }^{1}$. It is estimated that coronary heart disease may complicate $1 / 10,000$ pregnancies and may be potentially lethal for both the mother and the fetus ${ }^{2,3}$. In a series of published cases during the period from 1943 to 1997,33 pregnancies in women with previous infarction were reported, out of which, 16 were properly investigated ${ }^{2}$. The risks associated with subsequent pregnancies depend on such factors as the status of the coronary anatomy, the presence of myocardial ischemia, and the residual left ventricular function ${ }^{4}$. As reports in the literature about maternal and fetal management and outcome are limited, cardiologists and obstetricians feel insecure about handling these patients.

Hypertensive disorder of pregnancy is known to complicate $10 \%$ of gestations, causing an increase in maternal and perinatal morbidity and mortality. The incidence of that disorder is increased in patients with previous predisposing factors, such as nulliparity, multifetal gestation, hypertension, and diabetes, previous or familial history of preeclampsia, fetal hydrops, hydatidiform mole ${ }^{5}$. Maternal complications associated with the hypertensive disorder of pregnancy include the following: premature detachment of the placenta, pulmonary edema, respiratory distress, disseminated intravascular coagulation, cerebral hemorrhage, hepatic failure, renal failure ${ }^{5}$. Fetal complications include the follo-

Hospital Nossa Senhora da Conceição - Porto Alegre

Mailing address: Citânia Lúcia Tedoldi - Rua Santa Cecília, 1373/502 -

90420-041 - Porto Alegre, RS, Brazil wing: prematurity, intrauterine growth retardation, fetal and neonatal death ${ }^{5}$. The risk is higher in older women, those with preexisting vascular disease (arterial hypertension, renal disease, type I diabetes mellitus), in multifetal gestations, and in those women with complications in previous pregnancies ${ }^{6}$. Genetic forms of thrombophilia (tendency to the occurrence of thrombosis) are related to adverse gestational results. However, the value of a routine investigation in such cases is questionable ${ }^{6}$.

\section{Case Report}

A 40-year-old pregnant white female, gravida III (GIII) para II (PII), last delivery 18 years before, with an echographic gestational age of 23 weeks, sought medical care at the high-risk pregnancy unit of the Hospital Nossa Senhora da Conceição. She reported an inferior myocardial infarction at the age of 31 years and an anteroseptal myocardial infarction at the age of 38 years. After the latter event, coronary angiography showed a proximal segmentary lesion occupying $95 \%$ of the lumen of the anterior descending artery, a segmentary lesion of $50 \%$ in the right coronary artery, and a segmentary lesion of $50 \%$ in the medium third of the posterior ventricular branch of the right coronary artery. Ventriculography showed inferior akinesia and anteroapical hypokinesia (figs. 1 to 4). Based on these findings, the patient underwent myocardial revascularization with implantation of an internal thoracic artery bypass graft to the diagonal branch and saphenous vein bypasses to the anterior descending and right coronary arteries.

She also reported arterial hypertension and hyperlipidemia in the 2 preceding years, smoking for 10 years, and use of oral contraceptives until she discovered the pregnancy. Her mother had died of a stroke and her sister had had preeclampsia. In a routine assessment, ignoring the pregnancy but already at the $10^{\text {th }}$ week of gestation, the exercise test showed weak cardiorespiratory fitness, angina during exercise, at the second stage, and worsening of the previous alterations of the ST segment (straightening), representing residual ischemia. She used captopril at a dose of $37.5 \mathrm{mg} /$ day and SL nitrate when necessary.

On physical examination, the following variables were notable: body mass index of 22.7, blood pressure measured in the right upper limb with the patient sitting of 140/90m$\mathrm{mHg}$, heart rate of $84 \mathrm{bpm}$, systolic murmur (+/4+) in the left ventricular area, respiratory frequency of 20 breaths per mi- 


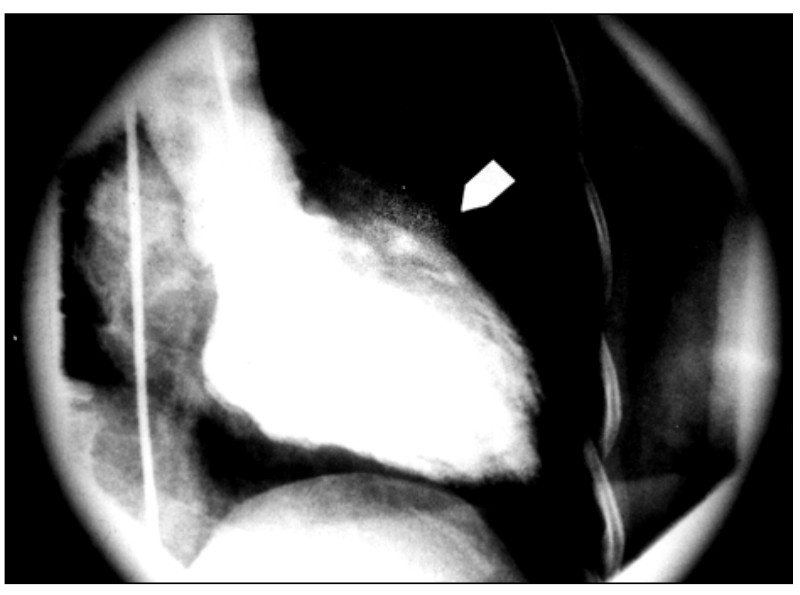

Fig. 1 - Ventriculography showing the anteroapical hypokinesia of the left ventricle.

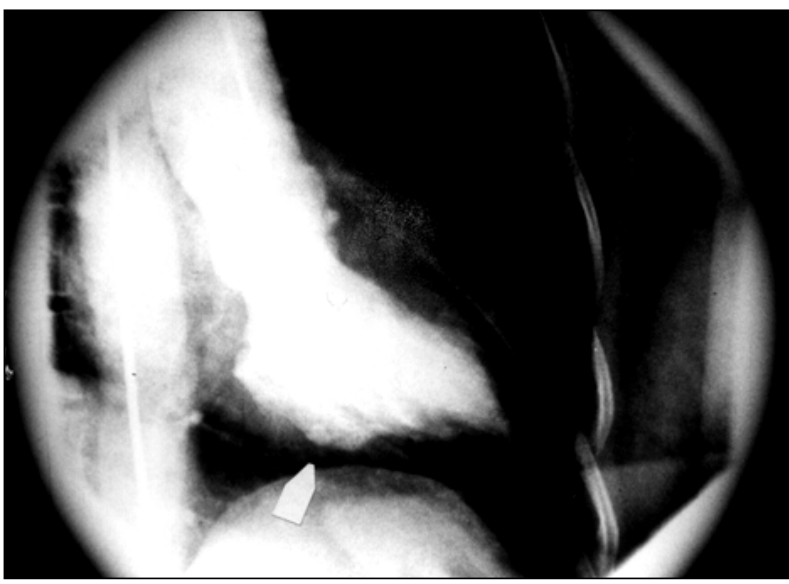

Fig. 2 - Ventriculography showing the inferior akinesia of the left ventricle.

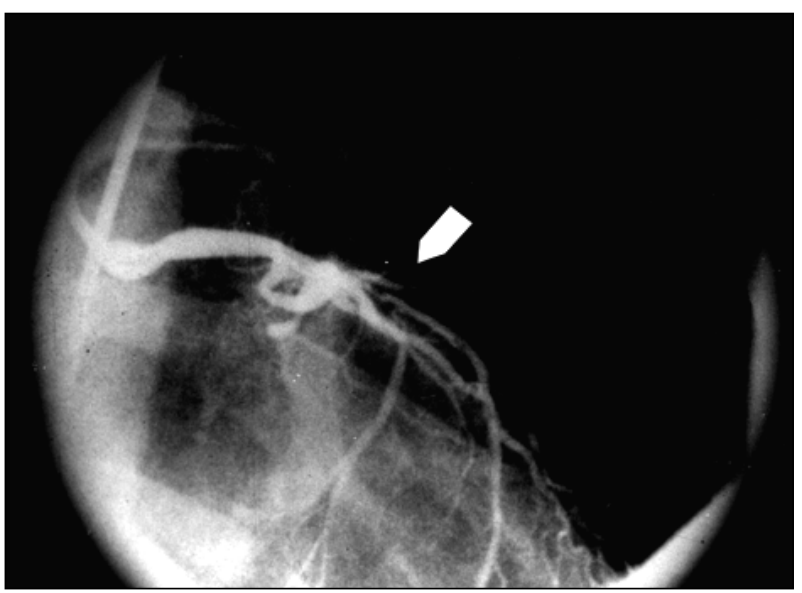

Fig. 3 - Coronary angiography showing a 95\% segmentary lesion with irregular margins in the proximal portion of the anterior descending artery.

nute, with diffuse pulmonary rhonchi, acyanosis, good peripheral perfusion, and no edema.

Laboratory tests were normal, except for the lipid profile, which showed the following values: total cholesterol of $244 \mathrm{mg} / \mathrm{dL}$; LDL-cholesterol of $142 \mathrm{mg} / \mathrm{dL}$; triglycerides of $421 \mathrm{mg} / \mathrm{dL}$. The electrocardiogram showed sinus rhythm, an inferior probably inactive area, and unspecific alterations of

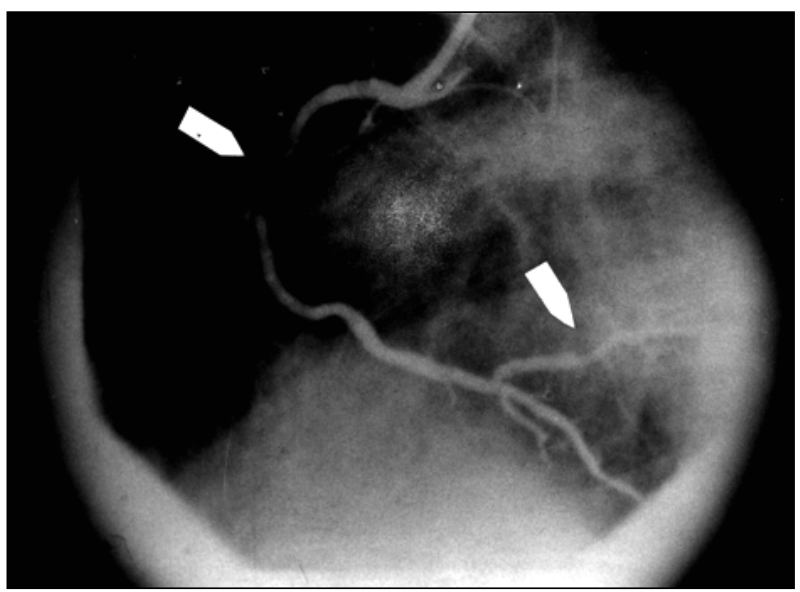

Fig. 4 - Coronary angiography showing a 50\% segmentary ulcerated and eccentric lesion with irregular margins in the right coronary artery, and a 50\% segmentary lesion in the medium third of the posterior ventricular branch of the right coronary artery.

ventricular repolarization (fig. 5). A maternal echocardiogram showed a left atrium of $35 \mathrm{~mm}$, shortening fraction $(\% \Delta \mathrm{D})$ of $19 \%$, ejection fraction of $45 \%$, mild enlargement in the left ventricle, diastolic left ventricle of $56 \mathrm{~mm}$ and systolic left ventricle of $45 \mathrm{~mm}$, segmentary contractile dysfunction with inferodorsal and septoapical hypokinesia, and mild mitral reflux. The fetal echocardiogram at the $24^{\text {th }}$ week of gestation was normal.

Pansinusitis was diagnosed and treated with ampicillin, nebulization, and respiratory physiotherapy, normalizing the pulmonary auscultation. The therapeutical management adopted was rest, diet for hyperlipidemia, suspension of captopril, acetylsalicylic acid at a dose of $100 \mathrm{mg} /$ day, atenolol at a dose of $100 \mathrm{mg} / \mathrm{day}$, and isosorbide mononitrate at a dose of $40 \mathrm{mg} / \mathrm{day}$ through oral via.

On ambulatory assessment at the gestational age of 26 weeks, the patient was asymptomatic, with blood pressure of $135 / 90 \mathrm{mmHg}$, and heart rate of $68 \mathrm{bpm}$. She came back at the gestational age of 30 weeks reporting sporadic uterine contractions. At that time her blood pressure measured in the right upper limb with the patient sitting was $160 / 100 \mathrm{~m}-$ $\mathrm{mHg}$, and the physiological decrease did not occur on left lateral decubitus. Her heart rate was $80 \mathrm{bpm}$ and the patient had no edema. At that time she was admitted to the hospital due to a diagnostic suspicion of preeclampsia, which was confirmed by laboratory tests (urea of $39 \mathrm{mg} / \mathrm{dL}$; creatinine of $0.9 \mathrm{mg} / \mathrm{dL}$; uric acid of $6.3 \mathrm{mg} / \mathrm{dL}$; clearance of endogenous creatinine of $86 \mathrm{~mL} / \mathrm{min}$; hematocrit of $39.4 \%$; hemoglobin of $13.2 \mathrm{~g} / \mathrm{mL}$; platelets $163,000 / \mathrm{mm} 3$; fibrinogen of $530 \mathrm{mg} / \mathrm{dL} ; \mathrm{LDH} 352 \mathrm{U} / \mathrm{L})$. The patient denied angina and the electrocardiogram remained unchanged. At the gestational age of 31 weeks, the obstetric echography showed an asymmetric retardation of the intrauterine growth. The Doppler blood flow test showed centralization of the fetal circulation. Amniocentesis was performed and fetal pulmonary immaturity was diagnosed. The patient was treated with rest in the position of left lateral decubitus, parenteral hydration, and oxygen therapy, heparin SC at the dose of $5000 \mathrm{U}$ every 12 hours, reduction in atenolol to $50 \mathrm{mg} / \mathrm{day}$, association of 


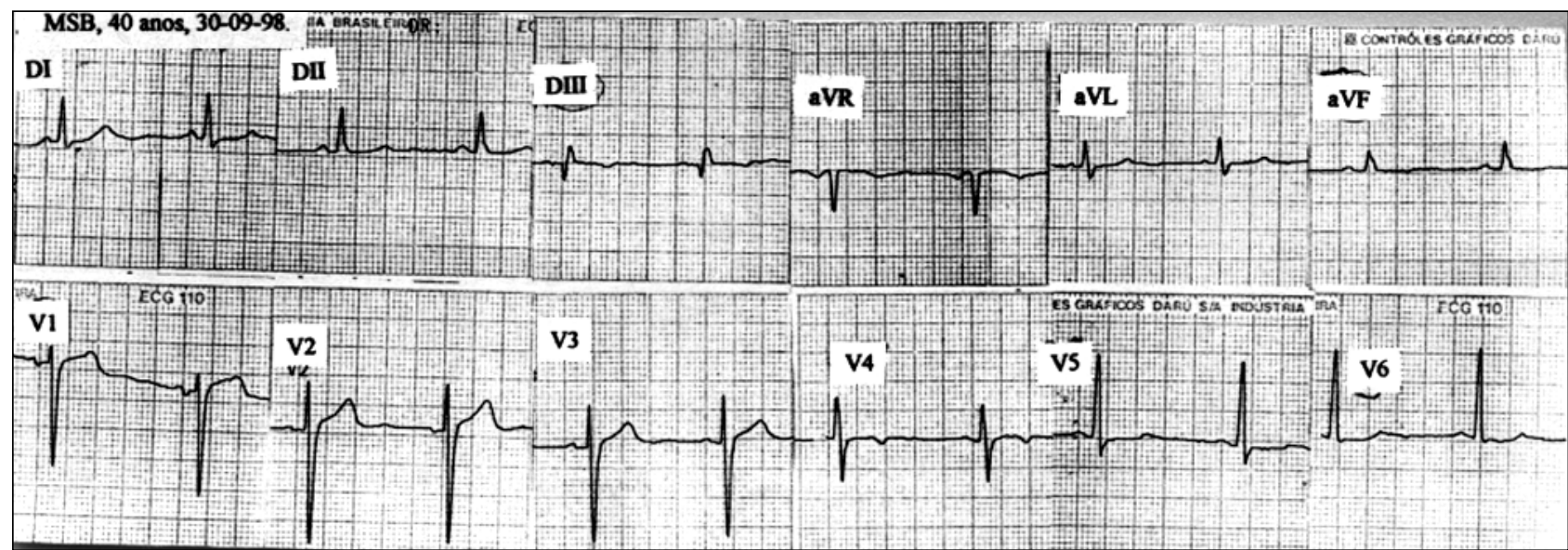

Fig. 5 - Electrocardiogram showing sinus rhythm, an inferior probably inactive area, and unspecific alterations of ventricular repolarization.

nifedipine $30 \mathrm{mg} /$ day orally and if necessary, betamethasone once a week. The acetylsalicylic acid and the isosorbide mononitrate were maintained. The fetus was monitored through cardiotocography and fetal biophysical profile. At the gestational age of 33-34 weeks, reduction in the variability of the fetal heart rate in association with late severe deceleration were verified, as was a fetal biophysical profile of $2 / 8$ with absolute oligohydramnios. The pregnancy was interrupted with a cesarean section under peridural anesthesia and tubal ligation was performed. No maternal problems occurred. The female newborn infant weighed $1,345 \mathrm{~g}$ and had an Apgar score of 1 at the first minute and 6 at the fifth minute. Despite the cardiorespiratory depression, the newborn responded well to the neonatal reanimating maneuvers, without progression to severe respiratory distress due to hyaline membrane disease. Pediatric gestational age (Capurro) was 36 weeks. The newborn infant remained hospitalized for treatment of septicemia and to gain weight. At the age of 3 months, the infant was healthy and weighed $4,000 \mathrm{~g}$. The placenta weighed $400 \mathrm{~g}$ and had some areas of infarct. Maternal hereditary thrombophilia was investigated and a deficiency (54\%) in the activity of the $S$ protein was revealed. C protein, antithrombin III, and plasminogen were nor$\mathrm{mal}$, and no mutations in the prothrombin and in the Factor Leiden factor $V$ were identified. Hyperhomocystinemia was not investigated. Three months after the delivery, the mother was asymptomatic with blood pressure of $110 / 80 \mathrm{mmHg}$, heart rate of $76 \mathrm{bpm}$, and she was using $25 \mathrm{mg} /$ day of captopril, $100 \mathrm{mg} /$ day of atenolol, $200 \mathrm{mg} /$ day of acetylsalicylic acid, and $20 \mathrm{mg} /$ day of lovastatin. The patient will be reassesed to confirm the deficiency in the activity of the S protein.

\section{Discussion}

Even though symptomatic ischemic heart disease in pregnancy is rare, if it is identified, follow-up by a multidisciplinary team during the gestational and puerperal periods is required, as well as counseling in regard to future pregnancies. The multidisciplinary team must comprise the following specialists: an obstetrician, a cardiologist, a nutritio- nist, a social worker, a psychologist, an anesthesiologist, a neonatologist, and a gynecologist with experience in following up high-risk pregnancy.

Among the risk factors for coronary heart disease, our patient had hypertension, hyperlipidemia, and oral contraceptive use in association with smoking ${ }^{4}$. As predisposing factors for the hypertensive disorders of pregnancy, she had chronic hypertension and a familial history of preeclam$\mathrm{psia}^{3}$. The risk of a gestation subsequent to 2 myocardial infarctions was associated with the presence of a mild segmentary left ventricular dysfunction (Shorte ning fraction of $19 \%$ and ejection fraction of $45 \%$ ) and residual ischemia ${ }^{2}$, despite the previous surgical myocardial revascularization. Therefore, maternal gestational risk was increased by age and hypertension with the superposing hypertensive disorder of pregnancy, which is characterized by an increase in vascular reactivity that may affect the coronary arterial flow ${ }^{2}$ and the flow of other important organs. The maternal gestational risk was also increased by the ischemic heart disease with sequela of 2 myocardial infarctions; mild left ventricular dysfunction accompanied by residual myocardial ischemia with the risk of decompensation due to the physiological hemodynamic overload of pregnancy.

Maternal therapeutical interventions comprised the following: suspension of captopril (this drug is associated with teratogenicity, severe toxicity to the fetus and newborn infant, which may include death ${ }^{7}$ ) and some measures to reduce oxygen consumption and increase oxygen supply to the myocardium (rest, blood pressure control, use of a beta-blocker, coronary artery vasodilator, and acetylsalicylic acid in a dosage with a lower risk of hemorrhage to the fetus). The patient also received a diet to control hyperlipidemia. She did not receive medication to lower lipids because no controlled studies exist proving the safety of using lipid-lowering drugs during pregnancy ${ }^{3}$. With the diagnosis of preeclampsia, which is associated with reduction in the flow through the uterine artery or the umbilical artery, or both ${ }^{8}$, even though it was classified as a mild form, a concern with assessment of fetal well-being existed, because the patient already had predisposing factors to intrauterine 
growth retardation, such as the use of beta-blocker ${ }^{3}$ and previous arterial disease. We decided to reduce the dose of atenolol and to prescribe nifedipine, which in addition to providing an appropriate control of the blood pressure, does not interfere with the uterus-placenta blood flow ${ }^{8}$.

Severe fetal hypoxia evidenced by centralization of the fetal circulation on the Doppler blood flow test creates a risk of death within 2 weeks ${ }^{9}$. As fetal pulmonary maturity was not assured when amniocentesis was performed, betamethasone was started and some measures to increase oxygen supply to the fetus and reduce the risks of thromboses were adopted. Severe maternal and obstetrical complications have been related to the presence of thrombophilias, mainly in white women ${ }^{6}$. Screening for hereditary thrombophilia showed deficiency in the activity of the $S$ protein, which should be reconfirmed because during pregnancy this activity may be physiologically decreased ${ }^{10}$. Delivery by cesarean section was an obstetrical indication (eminent fetal death) even though the vaginal via with analgesia is the preferred one in patients with hemodynamically stable ischemic heart disease. Medications such as betamimetics, ergot alkaloids, bromocriptine, and prostaglandins are contraindicated during pregnancy and puerperium because they may cause infarction or thrombosis, or both ${ }^{2}$.

Prematurity accounts for more than $50 \%$ of the morbidity and mortality among newborn infants without any congenital anomalies; $90 \%$ of the premature infants weighing between $1,250 \mathrm{~g}$ and $1,500 \mathrm{~g}$ survive ${ }^{11}$. The major complications include the following: respiratory distress, which ranges from transitory tachypnea of the newborn to hyaline membrane disease; septicemia; intraventricular hemorrhage; and necrotizing enterocolitis. The incidence of respiratory distress is inversely proportional to the weight percentile at birth ${ }^{12}$. Hyaline membrane consequent to pulmonary and thoracic cage immaturity and deficiency in surfactant affects $10 \%$ to $15 \%$ of the newborn infants weighing less than $2,500 \mathrm{~g}^{11}$.

Precocious neonatal mortality in the nursery of our hospital is comparable to that of the United States in the ' 80 s $(11 \%)$. At the Universidade Federal de Minas Gerais this mortality was reported as $31.2 \%$ in 1990, and in Latin American countries it was reported as $16 \%$ in 1981. In the very low-weight newborn infants, precocious neonatal mortality is about $18 \%$ and in $1 \%$ of these cases this mortality is related with respiratory diseases ${ }^{13}$.

Despite the presence of many predetermined factors that increase neonatal morbidity and mortality (prematurity, very low weight, intrauterine growth retardation, poor birth conditions, maternal age above 35 years) ${ }^{13}$, in association with maternal diseases such as hypertension, hypertensive disorder of the pregnancy, and ischemic heart disease, our newborn infant had a good outcome.

Maternal clinical stabilization prevented complications related to the underlying heart disease and the superposing hypertensive disorder of pregnancy (preeclampsia). Fetal monitoring in association with the adopted therapeutical interventions allowed the birth of a high-risk premature newborn infant, who was able to survive with the appropriate clinical management.

\section{References}

1. Raw KT. Epidemiology of coronary heart disease in women. In: Julian DG, Wenger NK. Women and Heart Disease. London: Mosby, 1997: 1-20.

2. Dufour PH, Ocelli B, Puech F. Pregnancy after myocardial infarction, Int J Gynaecol Obstet 1997; 59: 251-3.

3. Rutherford JD. Coronary artery disease in chilbearing age. In: Elkayam U, Gleicher N. Cardiac Problems in Pregnancy. $3^{\text {th }}$ Ed. New York: Wiley-Liss, 1998: 121-30

4. Webber MD, Halligan RE, Schumacher JA. Acute infarction, intracoronary thrombolysis and primary PTCA in pregnancy. Cathet Cardiovasc Diagn 1997; 42: 38-43.

5. Chiari RS, Frangieh AY, Sibai BM. Hypertension during pregnancy. In: Elkayam U, Gleicher N. Cardiac Problems in Pregnancy. $3^{\text {th }}$ Ed. New York: Wiley-Liss, 1998: 257-73.

6. Sibai BM. Thrombophilias and adverse outcomes of pregnancy - What should a clinician do? N Eng J Med. 1999; 340: 51-52.

7. Briggs GG, Freeman RK, Yaffe SJ. Drugs in Pregnancy and Lactation. $5^{\text {th }}$ Ed. Baltimore: Williams e Wilkins, 1998: 133c.
8. Moretti MM, Fairlie MF, Aki S, Khoury AD, Sibai BM. The effect of nifedipine therapy on fetal and placental waveforms in preeclampsia remote from term. Am J Obst Gynecol 1990; 163: 1844-8.

9. Schulman H. Doppler ultrasound in pregnancy. In: Elkayam U, Gleicher N. Cardiac Problems in Pregnancy. $3^{\text {th }}$ Ed. New York: Wiley-Liss, 1998: 615-27.

10. Montella KR, Ginsberg J Thromboembolic disease in pregnancy. In: Elkayam U, gleicher N. Cardiac Problems in Pregnancy. $3^{\text {th }}$ Ed. New York: Wiley-Liss, 1998: 232.

11. Trindade CEP. Prematuridade. Em Manual de Perinatologia, $2^{\text {a }}$ edição, MEDSI 1995, Cap 40: 512-37.

12. McIntire DD, Bloom SL, et al. Birth weight in relation to morbidity and mortality among newborns infants. N Eng J Med 1999; 340: 1234-8.

13. Varella IRS, Lopes ACS, Paniz L, Silveira LML, Ferreira NF, Sandrez MM. Perfil nosológico dos recém-nascidos do berçário do Hospital Nossa Senhora da Conceição. Apresentado no XVI Congresso Brasileiro de Perinatologia, Nov 1998, Salvador, Bahia 